\title{
An Analysis Of Interregional Migration In Texas: 1965-1970
}

\author{
Celia Morgan*
}

Even a cursory review reveals a burgeoning literature on the economic analysis of gross directional migration flows. The more recent research has concentrated on expanding and refining migration models which explain interstate migration over particular time periods [4]. These models neglect two aspects of migration: (1) the gross directional flows between relatively small geographical areas and (2) the stability over time of the parameters derived from the models. While this study is directed toward the former, the determinants of migration between state economic areas in Texas, the results also suggest that parameters derived from the analysis of a given time period do not necessarily hold for other time periods.

The economic analysis of migration has proceeded within the constructs of the classical theory of factor mobility. Comparative economic advantages to the individual which exist among areas are the motivating forces behind geographical mobility. Interarea migration thus improves the allocation of labor by geographically redistributing the existing population.

Empirical verification of the hypothesis implied above is complicated by the size of the area. For example, the analysis of gross directional migration between states implicitly assures homogeneous conditions within states and, therefore, may tend to ascribe to the average migrant a pattern of behavior which is characteristic of only persons who move long distances. The use of smaller spatial areas is not subject to this criticism, but is not without its price. If the areas are contiguous, there is an increased probability of defining a short distance movement, which represents a change of residence but no change of job, as part of a migration flow.

Gross migration between smaller spatial areas has been analyzed by two researchers. Lowry [12] analyzed gross directional migration between large standard metropolitan statistical areas during the period 1955-1960. Rogers [15] analyzed gross directional migration between state economic areas in California during the period 1955-1960. Conceptually the present study is similar to the Rogers study except that the time period is $1965-1970$.

*Southwest Texas State University, San Marcos, Texas. 


\section{THE MODEL}

The Lowry-Rogers model is used to investigate interarea migration flows in Texas. ${ }^{1}$ This model takes the following form.

(1) $\mathrm{Mi} \rightarrow \mathrm{j}=\mathrm{k}\left[\mathrm{Yj} / \mathrm{Yi} \cdot \mathrm{Ui} / \mathrm{Uj} \cdot \frac{\mathrm{LFi} \cdot \mathrm{LFj}]}{\mathrm{Dij}} \cdot \mathrm{u}\right.$

$\mathrm{Mi} \rightarrow \mathrm{j}=$ Number of persons 5 years of age and over, residing in SEA $j$ in 1970 who resided in SEA $i$ in 1965

Dij = highway mileage between the largest city of SEA i and that of SEA $j$

$\mathrm{Yi}, \mathrm{Yj}=$ mean wage and salary income in 1969 of families living in $\mathrm{i}$ and $\mathrm{j}$, respectively

$\mathrm{Ui}, \mathrm{Uj}=$ Unemployment as a percent of the civilian labor force at $i$ and $j$, respectively, during approximately the first week in April, 1970

$\mathrm{LFi}, \mathrm{LFj}=$ labor force eligibles, the number of persons between 15 and 64 years of age in 1965 at $i$ and $j$, respectively

$\mathrm{u}=$ random error

The model is specified in terms of gross directional flows between areas. The independent variables include factors in the origin area which prompt movement from it and factors in the destination area which cause it to be chosen. ${ }^{2}$ Thus, the model can be classified as a "push-pull" model. This is conceptually the most complete model if the objective is to explain migration behavior by the analysis of the migration decisionmaking process.

The dependent variable, $\mathrm{Mi} \rightarrow \mathrm{j}$, represents the number of persons moving from one area to another rather than the following dependent variables sometimes used in migration analysis: (1) The proportion of total out-migrants from one area who chose a particular destination, (2) net migration, or (3) gross in- or out- migration for a single area. Research concerned with explaining the proportion of out-migrants who chose particular destinations is primarily concerned with the allocation of resources. ${ }^{3}$ The analysis of net migration or net migration rates, such as the studies of Blanco [1] or Lowry [12], is useful to planners concerned with forecasting population change due to migration. Defining the dependent variable as a measure of net migration implicitly ignores the fact that net migration is the complex resultant of two opposing forces, gross in- and gross out-migration. ${ }^{4}$ Analysis of gross in- or outmigration of a single area provides some insight into the decision-making process of migrants with respect to the characteristics of an area which prompt in and out movement. It does not, however, investigate the 
complete decision-making process, for example, why persons in one area decide to move and choose a particular destination. Insight into these decisions can only be obtained through the analysis of gross directional flows between areas.

The Lowry-Rogers model incorporates both economic and "gravity" variables. The simple gravity model [9] predicts that the flow of persons between two places is random; the size of the flow depending on the size of the places and the distance between them. The number of labor force eligibles at origin and destination is used as a measure of the place size. The gravity model predicts that gross migration will be positively related to both origin and destination size.

An inverse relationship between distance and migration is suggested by two hypotheses. ${ }^{5}$ Economic analysis suggests that distance acts as a proxy for the cost of movement from one area to another. The private costs of movement can be divided into measurable money costs (the outof-pocket costs of movement as well as opportunity costs-earnings foregone while traveling, searching for, and learning a new job), implied cost [16] (subjective or "psychic" costs-the cost of detaching oneself from familiar surroundings) and information costs [14] (distance acts as an impediment to the flow of information; the greater the distance between areas, the more limited the flow of information). Thus, the greater the distance between areas, the higher the cost and the lower the migration flows between areas.

Stouffer's hypothesis of interviewing opportunities [17, 18] also suggests an inverse relationship between migration and distance. This analysis assumes that individuals move to find the opportunity they want. The greater the number of intervening opportunities, the fewer the number of persons who will proceed to the more distant area. Distance here is simply a proxy for the number of intervening opportunities.

The rationale for the relationships between migration flows and the other independent variables implied by the model are similar to those used by Lowry [12] and by Rogers [15]. The classical theory of factor mobility which treats the migration decision as an extension of the theory of consumer choice suggests that the migration decision involves a comparison of alternative expected income streams, i.e., the expected income streams forthcoming if one does not move or moves to another area. The analysis predicts that if the expected income stream in the origin area is lower than that in the destination area, the potential migrant moves. Consequently, gross migration from one area to another should be negatively related to expected income at the origin and positively related to expected income at the destination.

Expected income cannot be observed directly. Two observable components upon which expected income is based can be observed. Mean wage and salary income in each area provides information upon which potential earnings in an area can be estimated, and the unemployment rate is a proxy for a measure of the varying degrees of uncertainty. ${ }^{6}$ 
Gross migration from one area to another should be negatively related to observed mean wage and salary income at the origin and positively related to it at the destination. The risk of unemployment and, therefore, the cessation of the income stream is one factor associated with uncertainty. The area unemployment rate is used as an indicator of the degree of this risk. Specifically, the higher the unemployment rate, the greater the risk. Assuming that individuals are risk averters, gross migration from one area to another should be positively related to origin unemployment and negatively related to destination unemployment.

\section{RESULTS}

The Lowry-Rogers model specified in equation (1) becomes linear under a log transformation, and the parameters can be estimated by multiple linear regression. The coefficients thus derived represent the (partial) elasticity of gross migration with respect to the independent variable. The estimated relationship was of the following form; the expected sign of the coefficient appears in parentheses.

(2) $\ln \mathrm{Mi} \rightarrow \mathrm{j}=\ln a+\beta_{1} \ln \mathrm{Ui}+\beta_{2} \ln \mathrm{Uj}+\beta_{3} \ln \mathrm{Yi}+\beta_{4} \ln \mathrm{Yj}+$

$$
\begin{array}{llll}
\left(\beta_{1}>0\right) & \left(\beta_{2}<0\right) & \left(\beta_{3}<0\right) & \left(\beta_{*}>0\right)
\end{array}
$$

$$
\begin{gathered}
\beta_{5} \ln \mathrm{LFi}+\beta_{6} \ln \mathrm{LFi}+\beta_{\overline{7}} \ln \mathrm{Dij} \\
\left(\beta_{5}>0\right) \quad\left(\beta_{6}>0\right) \quad\left(\beta_{\bar{i}}<0\right)
\end{gathered}
$$

The results of fitting gross inter-SEA migration flows for all SEA's in Texas for the period 1965 to 1970 to equation (2) appear in Table I. All of the regression coefficients have the expected sign, and each coefficient is significantly different from zero at least at the 5 per cent level of confidence. The " $F$ " ratio for the regression as a whole is highly significant, and the coefficient of determination indicates that two-thirds of the variance of gross migration flows between Texas state economic area is explained.

The movement of migrants exhibits the largest elasticity for the distance variable. Size of the area is next most important. Somewhat lower elasticities are obtained for origin income and unemployment rates and destination income. Migrants respond least to a percentage change in the destination unemployment rate.

This model yields a distance elasticity which appears larger than other studies have found. ${ }^{7}$ According to the regression results an increase in destination income of 10 per cent would be offset by an increase in distance of only 3.9 per cent. At the mean of the annual incomes (measured in 1969 dollars) and distance variables, these percentages imply that a migrant would be indifferent to an increase of $\$ 812$ per year if he had to move an additional 160 miles to realize the increase, ceteris paribus. Stated another way, the regression implies that someone living in Dallas will be indifferent to moving either to Brownwood or to Bryan unless he expects to receive an increment of more than $\$ 812$ a year, ceteris paribus. 


\section{TABLE I}

Gross Inter-Regional Migration, 1965-1970: Logarithmic Regression Coefficients (B) and Standard Errors of Regression Coefficients [ ]

\begin{tabular}{lc}
\hline & $\begin{array}{c}\text { Intercept } \\
\text { or Regression } \\
\text { Coefficient } \\
\text { (Elasticity) }\end{array}$ \\
\hline Independent Variable & $-1.09225^{\mathrm{a}}$ \\
\hline Distance (Dij) & {$[.04551]$} \\
Origin Income (Yi) & $.57911^{\mathrm{a}}$ \\
Destination Income (Yj) & $.18315]$ \\
Origin Unemployment Rate (Ui) & $.42086^{\mathrm{a}}$ \\
Destination Unemployment Rate (Uj) & $.418315]$ \\
Origin Labor Force Eligibles (LFi) & {$\left[10756^{\mathrm{a}}\right.$} \\
Destination Labor Force Eligibles (LFj) & $.26569^{\mathrm{a}}$ \\
Intercept & {$[.10082]$} \\
$\mathrm{R}^{2}$ & $.69883^{\mathrm{a}}$ \\
S.E.E. & {$[.03764]$} \\
"F" Ratio & $.76715^{\mathrm{a}}$ \\
Degrees of Freedom & {$[.03715]$} \\
\hline
\end{tabular}

asignificantly different from zero at least at the 5 percent level of significance

The results of researchers concerned with inter-state migration suggest that this may be an overstatement of the distance elasticity. Greenwood [5] shows that if a migrant stock variable is included in the model, the distance elasticity of migration is reduced. Levy and Wadycki [11,24] argue that the distance elasticity of migration will be overstated if the model fails to include variables which act as proxies for intervening opportunities.

Lowry and Rogers found that the migration process was asymmetrical with respect to origin and destination characteristics during the 19551960 period. ${ }^{8}$ That is, while the "pull" factors (relatively attractive economic conditions at destinations) did attract in-migrants, the "push" resulting from adverse economic conditions did not stimulate movement out of origin areas. ${ }^{9}$ The results of this study suggest that this asymmetry was not present in the patterns of all migrant flows in Texas during the period 1965-1970.

\section{Migration Flows by Class of Area at Origin and Destination}

One reason for the difference in the results presented here and the Lowry results could be the different types of areas analyzed. Lowry 
analyzed only SMSA to SMSA migration flows. Rogers analyzed total inter-area migration flows within California as well as four types of migration flows: SMSA to SMSA, nonSMSA to nonSMSA, SMSA to nonSMSA, and nonSMSA to SMSA. The asymmetry suggested by Rogers results for all was not corroborated completely when the model was fitted to migration streams differentiated by class of area at origin and destination by using separate regression models for each class of pairs of areas. While the model provided a better accounting of flows originating from metropolitan areas, the origin wage coefficient was significantly different from zero at the 5 per cent level of confidence in flows between non-metropolitan areas.

The results from fitting the model to the 1965-1970 migration flows within Texas classified by metropolitan and non-metropolitan origins and destinations are presented in Table II. These results suggest that the model provides a better explanation of the variance of gross flows from metropolitan areas. More than three-fourths of the variance of gross flows from metropolitan areas is explained by the model in contrast to slightly more than one-half of the variance of gross flows from nonmetropolitan areas.

The coefficient for destination wages is significantly different from zero at the 5 per cent level of confidence in the regressions concerned with flows to non-metropolitan areas only. These results are consistent with Roger's results and imply that people will not move to non-metropolitan areas unless they expect an increase in income.

Although the coefficient for origin wages is significantly different from zero at the 5 per cent level of confidence in all four regressions, it has the wrong sign when the model is fitted to flows from non-metropolitan areas. This suggests that migration responses differ by the class of origin area. An explanation may be that higher income levels in nonmetropolitan areas permit a greater amount of movement out of the area. This result, coupled with the lack of statistical significance of the destination wage coefficient when the model is fitted to the SMSA to SMSA matrix suggests that rural-urban migration may be enhanced by relatively higher income levels in the rural areas. This is reasonable since rural-urban migration is selective by age. If younger members of rural communities are more likely to move, higher family incomes may encourage relatively greater movement out of these communities.

Classification of migration flows by metropolitan and non-metropolitan origin suggests that the elasticity of migration with respect to unemployment rates also differ by class of sub-region..$^{10}$ In fitting the model to the migration flows from non-metropolitan areas, the coefficients for origin unemployment rates have the correct sign and are significantly different from zero at the 5 per cent level of confidence. This suggests that persons are pushed out of rural areas by high unemployment rates. This does not appear to be the case for migrants from metropolitan areas. In the regression of flows from metropolitan areas, the sign of the coeffi- 


\section{TABLE II}

Gross Inter-Regional Migration from SMSA's and Non-SMSA's 1965-1970: Logarithmic Regression Coefficients (B) and Standard Errors of Regression Coefficients [ ]

\begin{tabular}{|c|c|c|c|c|}
\hline \multirow[b]{2}{*}{ Independent Variable } & \multicolumn{4}{|c|}{ Intercept or Regression Coefficient (Elasticity) } \\
\hline & $\begin{array}{l}\text { Flows from } \\
\text { SMSA to SMSA }\end{array}$ & $\begin{array}{l}\text { Flows from } \\
\text { SMSA to Non-SMSA }\end{array}$ & $\begin{array}{l}\text { Flows from } \\
\text { Non-SMSA to SMSA }\end{array}$ & $\begin{array}{l}\text { Flows from } \\
\text { Non-SMSA to Non-SMSA }\end{array}$ \\
\hline Distance (Dij) & $\overline{[} . .90693^{\mathrm{a}}$ & $\begin{array}{l}-1.22549^{\mathrm{a}} \\
{[.08327]}\end{array}$ & $\begin{array}{l}-1.29695^{\mathrm{a}} \\
{[.09803]}\end{array}$ & $\begin{array}{l}-1.07819^{\mathrm{a}} \\
{[.09649]}\end{array}$ \\
\hline Origin Income (Yi) & $\begin{array}{r}4.03213^{\mathrm{a}} \\
{[.61732]}\end{array}$ & $\begin{array}{c}-3.81182^{\mathrm{a}} \\
{[.47996]}\end{array}$ & $\begin{array}{r}1.82542^{\mathrm{a}} \\
{\left[\begin{array}{r}.56993]\end{array}\right]}\end{array}$ & $\begin{array}{r}1.74021^{\mathrm{a}} \\
{\left[\begin{array}{r}.51242]\end{array}\right]}\end{array}$ \\
\hline Destination Income ( $\mathrm{Yj})$ & $\begin{array}{c}-.22793 \\
{[.61736]}\end{array}$ & $\begin{array}{r}1.45944^{\mathrm{a}} \\
{\left[\begin{array}{r}.47996]\end{array}\right]}\end{array}$ & {$\left[\begin{array}{l}.91485 \\
.82318]\end{array}\right.$} & $\begin{array}{r}2.13621^{\mathrm{a}} \\
{\left[\begin{array}{r}.50032]\end{array}\right.}\end{array}$ \\
\hline Origin Unemployment Rate (Ui) & $\begin{array}{r}-.67376^{\mathrm{a}} \\
{[.27181]}\end{array}$ & $\begin{array}{c}-.67222^{\mathrm{a}} \\
{[.31177]}\end{array}$ & $\begin{array}{r}.96507^{\mathrm{a}} \\
{[.19362]}\end{array}$ & $\begin{array}{l}.67304^{\mathrm{a}} \\
{[.16870]}\end{array}$ \\
\hline Destination Unemployment Rate (Uj) & 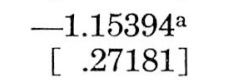 & $\begin{array}{c}-.10226 \\
{[.16302]}\end{array}$ & $\begin{array}{cl}- & .43256 \\
{[} & .36927]\end{array}$ & $\begin{array}{l}.09890 \\
{[.14466]}\end{array}$ \\
\hline Origin Labor Force Eligibles (LFi) & $\begin{array}{l}.99556^{\mathrm{a}} \\
{[.08132]}\end{array}$ & 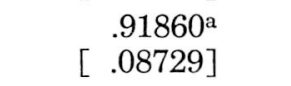 & {$\left[\begin{array}{l}.69558^{\mathrm{a}} \\
{[.06089]}\end{array}\right.$} & $\begin{array}{r}.49528^{\mathrm{a}} \\
{[.07025]}\end{array}$ \\
\hline Destination Labor Force Eligibles ( $\mathrm{LFj}$ ) & $\begin{array}{r}.87349^{\mathrm{a}} \\
{[.06090]}\end{array}$ & 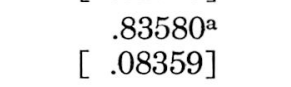 & {$\left[\begin{array}{l}.69558^{\mathrm{a}} \\
{[.08132]}\end{array}\right.$} & {$\left[\begin{array}{l}.49528^{\mathrm{a}} \\
{[.08690]}\end{array}\right.$} \\
\hline Intercept & 30.27257 & -5.89142 & -28.32361 & -33.14223 \\
\hline $\mathrm{R}^{2}$ & $83.53 \%$ & $75.81 \%$ & $69.21 \%$ & $51.48 \%$ \\
\hline S.E.E. & .5837 & .7199 & .8547 & .7564 \\
\hline “F” Ratio & 144.499 & 103.839 & 74.482 & 35.018 \\
\hline Degrees of Freedom & 202 & 232 & 232 & 232 \\
\hline
\end{tabular}

asignificantly different from zero at least at the 5 percent level of significance 
cient for origin unemployment rates is opposite to that expected on $a$ priori grounds, and both coefficients are significantly different from zero at the 5 per cent level of confidence. One might expect this result when the model is fitted to the SMSA to non-SMSA matrix if wages in metropolitan areas are significantly higher than wages in non-metropolitan areas. Here even with higher unemployment rates, the expected income stream might still be higher than that available elsewhere. ${ }^{11}$

Destination unemployment rates apparently enter only the migration decision of migrants moving from one metropolitan area to another. The coefficient for destination unemployment rates has the correct sign and is significantly different from zero at the 5 per cent level of confidence when the model is fitted to the SMSA to SMSA matrix.

The distance elasticity of migration varies by class of area. The distance coefficient in the analysis of flows to and from metropolitan areas is the lowest for any pair of area class. ${ }^{12}$ Distance elasticity is larger for migration flows from non-metropolitan areas. Migrants from rural areas may be more sensitive to distance. The above result could reflect the tendency for rural to urban migrants to usually select the nearest metropolitan area.

\section{The Stability of the Derived Parameters over Time}

A second reason for the differences in the results presented here and the Lowry and Rogers results could be that migration responses differ in different time periods. The $1955-1960$ period includes the 1958 recession while the 1965-1970 time period was one of uninterrupted economic growth. It may be that during recessionary periods, individuals respond positively to economic conditions at destination but are not "pushed out" of origin areas by adverse economic conditions. On the other hand, during periods of more rapid economic growth which does not occur uniformly among areas, individuals respond to adverse economic conditions in the origin area and move, their destination determined by the expected income stream at destination and the probability of obtaining it.

To test whether differences during two different time periods affected the migration decision, the model was fitted to Texas migration flows classified by metropolitan and non-metropolitan origin and destination which occurred during the period 1955-1960 and 1965-1970. In order to obtain comparability between the two periods, median family income, rather than mean wage and salary income, was used as the measure of potential earnings in an area. Mean wage and salary income data are not available for 1959 [21].

The results for both periods for migration flows classified by metropolitan and non-metropolitan origin and destination are presented in Tables III and IV. The analysis of variance technique developed by Chow [2] tests whether coefficients estimated using two data sets are equal. The Chow test shows a significant difference at the one per cent level of confidence in the estimated coefficients for the two time periods 
for each class of pairs of areas. This difference, which occurred over the decade, in the responsiveness of migration flows within Texas to area characteristics suggests that one reason for the difference in the initial Texas results and the Rogers and Lowry results is due to the different time periods used.

The results in Table III suggest that migration flows from metropolitan area were more responsive to origin economic conditions during the 1965-1970 period. The size of the origin income coefficient is larger in the 1965-1970 regressions. This suggests that relatively low origin income levels exert a greater push out of the area. While the origin unemployment rate coefficient in the 1965-1970 regressions has a sign opposite to that expected on a priori grounds, it is significantly different from zero at the five per cent level of confidence. In the 1955-1960 regressions the origin unemployment rate coefficient is not significantly different from zero at the five per cent level of confidence.

The results from fitting the model to flows from non-metropolitan areas (Table IV) suggest that the "push" factor of relatively high unemployment rates operates during periods of economic growth. The origin unemployment rate coefficient has the correct sign and is significantly different from zero in the 1965-1970 regressions; it is not in the 1955-1960 regressions. This greater sensitivity of migration flows to origin economic conditions during the 1965-1970 period suggests that the "push" factor of adverse origin economic conditions operates more cogently during periods of economic growth which does not occur uniformly among areas.

\section{CONCLUSIONS}

The findings presented here suggest that gross directional migration flows within Texas from 1965 to 1970 were responsive to differences in economic opportunity. There is a difference in the results, however, when the data are disaggregated by class of area at origin and destination. Thus in the analysis of relatively small spatial areas, the use of aggregate data is suspect because of changing weights.

The results presented suggest that economic opportunities at origin and destination enter the migration decision differently depending on the type of area. Persons moving from metropolitan areas respond to relatively low origin wages and move whereas persons moving from nonmetropolitan areas are pushed out by relatively high origin unemployment rates. Migrants to non-metropolitan areas are pulled by relatively high destination wages, but migrants to metropolitan areas respond to relatively low unemployment. These differences could reflect varying degrees of importance which individuals with different backgrounds place on wages and the probability of employment which together determine the expected income stream.

There is a difference in the coefficients estimated using two time periods when the analysis is extended to migration flows within Texas 


\section{TABLE III}

Gross Inter-Regional Migration 1955-1960 and 1965-1970 Logarithmic Regression Coefficients (B) and Standard Errors of Regression Coefficients [ ]

\begin{tabular}{|c|c|c|c|c|}
\hline \multirow[b]{3}{*}{ Independent Variable } & \multicolumn{4}{|c|}{ Intercept or Regression Coefficient (Elasticity) } \\
\hline & \multicolumn{2}{|c|}{ Flows from SMSA to SMSA } & \multicolumn{2}{|c|}{ Flows from SMSA to Non-SMSA } \\
\hline & $1955-1960$ & $1965-1970$ & 1955-1960 & $1965-1970$ \\
\hline Distance (Dij) & $\begin{array}{r}-0.81399^{a} \\
{[0.04963]}\end{array}$ & $\begin{array}{r}-0.90802^{\mathrm{a}} \\
{[0.06550]}\end{array}$ & $\begin{array}{r}-1.19129^{\mathrm{a}} \\
{[0.07629]}\end{array}$ & $\begin{array}{r}-1.23890^{\mathrm{a}} \\
{[0.08271]}\end{array}$ \\
\hline Origin Income ( Yi) & $\begin{array}{r}-0.73858^{\mathrm{a}} \\
{[0.45634]}\end{array}$ & $\begin{array}{r}-3.47665^{\mathrm{a}} \\
{[0.56461]}\end{array}$ & $\begin{array}{r}-0.58547 \\
{[0.58967]}\end{array}$ & $\begin{array}{r}-3.40848^{\mathrm{a}} \\
{[0.64335]}\end{array}$ \\
\hline Destination Income ( $\mathbf{Y j}$ ) & $\begin{array}{c}-0.57478 \\
{[0.45659]}\end{array}$ & $\begin{array}{c}0.38582 \\
{[0.56924]}\end{array}$ & $\begin{array}{r}1.41985^{\mathrm{a}} \\
{[0.23539]}\end{array}$ & $\begin{array}{r}1.07622^{\mathrm{a}} \\
{[0.33643]}\end{array}$ \\
\hline Origin Unemployment Rate (Ui) & $\begin{array}{c}-0.14089 \\
{[0.12267]}\end{array}$ & $\begin{array}{r}-0.81068^{a} \\
{[0.28869]}\end{array}$ & $\begin{array}{c}0.00691 \\
{[0.16832]}\end{array}$ & $\begin{array}{r}-0.82539^{\mathrm{a}} \\
{[0.32876]}\end{array}$ \\
\hline Destination Unemployment Rate (Uj) & $\begin{array}{r}0.67783^{\mathrm{a}} \\
{[0.12267]}\end{array}$ & $\begin{array}{r}-1.21680^{\mathrm{a}} \\
{[0.29159]}\end{array}$ & $\begin{array}{c}0.23740 \\
{[0.17082]}\end{array}$ & $\begin{array}{c}-0.00828 \\
{[0.17341]}\end{array}$ \\
\hline Origin Labor Force Eligibles (LFi) & $\begin{array}{r}0.83678^{\mathrm{a}} \\
{[0.04593]}\end{array}$ & $\begin{array}{r}0.88528^{\mathrm{a}} \\
{[0.05545]}\end{array}$ & $\begin{array}{r}0.73674^{\mathrm{a}} \\
{[0.06115]}\end{array}$ & $\begin{array}{r}0.85973^{\mathrm{a}} \\
{[0.06337]}\end{array}$ \\
\hline Destination Labor Force Eligibles ( LFj) & $\begin{array}{r}0.82939^{a} \\
{[0.04593]}\end{array}$ & $\begin{array}{r}0.88034^{\mathrm{a}} \\
{[0.05512]}\end{array}$ & $\begin{array}{r}0.73182^{\mathrm{a}} \\
{[0.06291]}\end{array}$ & $\begin{array}{r}0.87117^{\mathrm{a}} \\
{[0.07954]}\end{array}$ \\
\hline Intercept & 3.23925 & 27.50437 & -11.87983 & 14.59585 \\
\hline $\mathbf{R}^{2}$ & $87.07 \%$ & $83.03 \%$ & $74.34 \%$ & $75.83 \%$ \\
\hline S.E.E. & 0.4459 & 0.5894 & 0.6822 & 0.7195 \\
\hline “F” Ratio & 194.267 & 141.196 & 96.003 & 103.992 \\
\hline Degrees of Freedom & 202 & 202 & 232 & 232 \\
\hline
\end{tabular}

asignificantly different from zero at least at the 5 percent level of significance 


\section{TABLE IV}

Gross Inter-Regional Migration 1955-1960 and 1965-1970 Logarithmic Regression Coefficients (B) and Standard Errors of Regression Coefficients [ ]

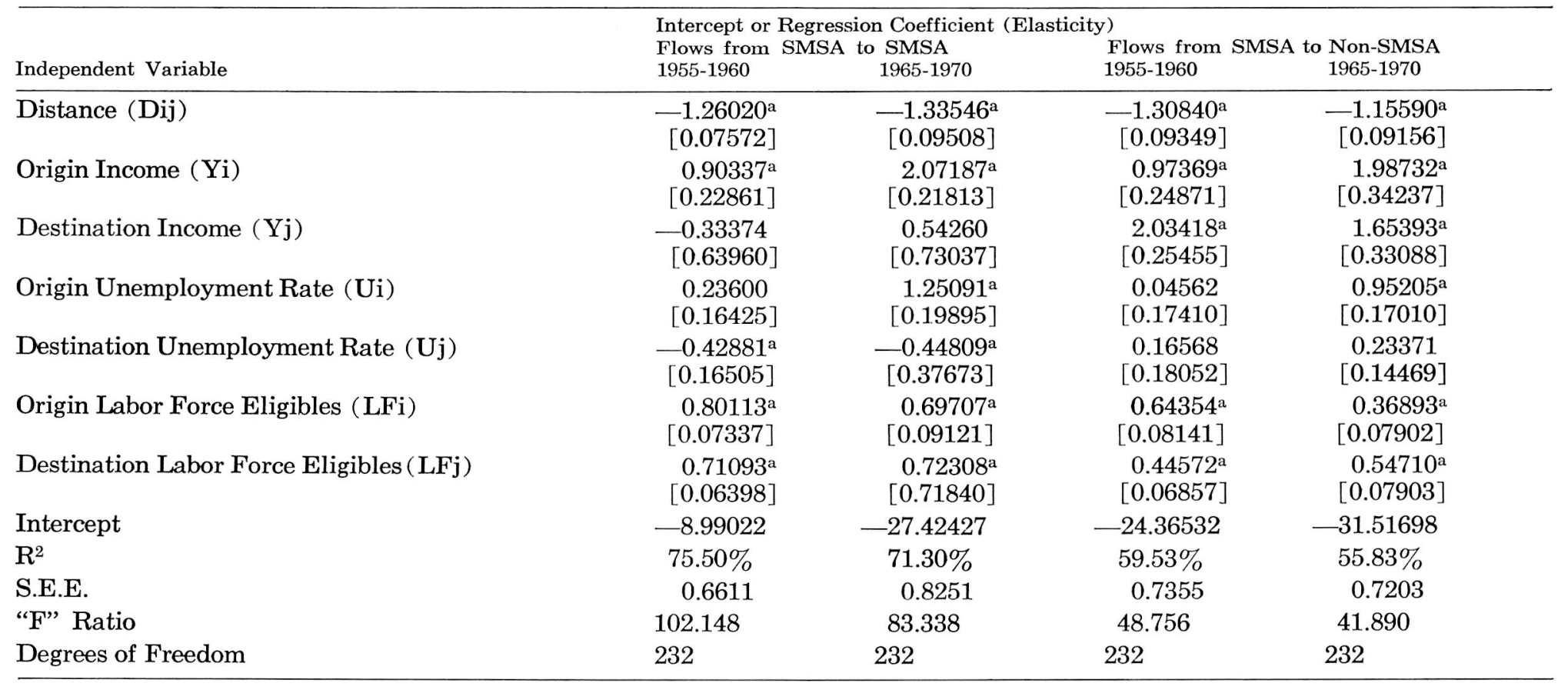

asignificantly different from zero at least at the 5 percent level of significance 
which occurred between 1955-1960. The inter-temporal comparison suggests migrants exhibited a greater sensitivity to origin economic conditions during the 1955-1960 period. This greater responsiveness to origin economic conditions during the 1965-1970 period suggests that policies designed to effect a redistribution of population through increased mobility may be more effective during periods of economic growth.

\section{FOOTNOTES}

1The data comprise migration flows between state ecoonmic areas in Texas over the 1965-1970 time period. These data are contained in the report of the 1970 census [19,20]. The distance between areas was highway mileage computed from data contained in an interstate road atlas [8].

${ }_{2}^{2}$ An anonymous referee has commented that this model, by defining the $\mathrm{Yi}, \mathrm{Yj}, \mathrm{Ui}$, and $\mathrm{Uj}$ as of the end of the migration interval, is subject to what Greenwood has termed the "simultaneity bias" because the system of equations is not simultaneous but is treated as if it were. A more appropriate specification of the model would define these variables as of the beginning of the migration interval, an inter-censal year for which census data is not available. Taking all of the variables as of the beginning of the migration interval probably would not alter the conclusions, but the regression coefficients would be altered slightly. The variables $L F i$ and $L F j$ are defined as of the beginning of the migration interval. These variables have been estimated from census data by straight line interpolation.

${ }^{3}$ Greenwood [5] and Wadycki [23] have investigated this aspect of migration. The question is interesting, but such research does not explain why people move. This is required to predict migration behavior.

4Fabricant [3] and Greenwood [6] argue that net migration models are reduced form equations from structural models specified in terms of gross migration.

5See Miller [13] for one attempt to determine which hypothesis is consistent with observed behavior.

${ }_{6}^{6}$ Mean wage and salary does not represent a measure of potential earnings for all migrants. In any one area wage and salary incomes vary among individuals with some individuals earning higher than average incomes and others earning lower than average incomes depending on occupation and/or industry of employment as well as personal characteristics. Also, potential migrants may expect higher or lower than average incomes depending on occupation and/or industry of employment as well as personal characteristics. Mean wage and salary income represents a measure of potential earnings for the average migrant.

iLowry reported a distance coefficient of -.83043, and Rogers reported a distance coefficient of -.68717 .

8In Lowry's analysis of inter-metropolitan directional flows of migration, the coefficients for destination wage levels and unemployment rates were significantly different from zero but the coefficients for origin variables were not [12, pp. 7-33]. Rogers [15] obtained essentially the same results in his analysis of inter-regional migration within California.

${ }^{9}$ This asymmetry was first noticed by Lansing and Mueller [10].

10We can not compare these results with Rogers' results because, when the Rogers model was fitted to flows disaggregated by class of sub-region at origin and destination, unemployment rates were not included as independent variables. "Because of the unexplainable behavior of the unemployment variable, we have removed it from the model ...", Rogers [12, p. 264]. There is, of course, the possibility of simultaneity among the variables. The single equation model does not allow for interaction effects, and an argument can be made for formulating a model which allows for interaction.

11Hall [7] has used this line of reasoning.

12 It is still larger than the coefficient reported by Rogers [15, p. 265] and by Lowry [12, pp. 15-17].

13These data are contained in the reports of the 1960 census [21, 22].

\section{REFERENCES}

[1] Blanco, Cicely. "Prospective Unemployment and Interstate Population Movements." Review of Economics and Statistics, 46 (May, 1964), 221-222.

[2] Chow, Gregory C. "Tests of Equality between Sets of Coefficients in Two Linear Regressions." Econometrica, 28 (July, 1960), $591-605$

[3] Fabricant, Ruth A. "An Expectational Model of Migration." Journal of Regional Science, 10 (April, 1970), 13-24.
[4] Greenwood, Michael J. "Research on Internal Migration in the United States: A Survey." Journal of Economic Literature, 13 (June, 1975), 397-433.

[5] . "An Analysis of the Determinants of Geographic Labor Mobility in the United States." Review of Economics and Statistics, 51 (May, 1969), 189-194.

[6] "Lagged Response in the Decision to Migrate: A Reply." Journal of Regional Science, 12 (August, 1972), 311-324. 
[7] Hall, Robert E. "Why Is the Unemployment Rate So High at Full Employment?" Brookings Papers on Economic Activity, 3 (1970), 369-410.

[8] Interstate Road Atlas. New York: Rand McNally, 1973.

[9] Isard, Walter, et al. Methods of Regional Analysis. New York: The Technology Press and John Wiley \& Sons, Inc., 1960.

[10] Lansing, John B. and Mueller, Eva. The Geographic Mobility of Labor. Ann Arbor, Michigan: Survey Research Center, Institute for Social Research, The University of Michigan, 1967.

[11] Levy, Mildred B. and Wadycki, Walter J. "What is the Opportunity Cost of Moving? Reconsideration of the Effects of Distance on Migration." Economic Development and Cultural Change, 22 (January, 1974), 198214.

[12] Lowry, Ira S. Migration and Metropolitan Growth: Two Analytical Models. San Francisco: Chandler Publishing Co., 1966.

[13] Miller, Edward. "A Note on the Role of Distance in Migration: Costs of Opportunity versus Intervening Opportunities." Journal of Regional Science, 12 (December, 1972), 475-478.

[14] Nelson, Phillip. "Migration, Real Income and Information." Journal of Regional Science, 1 (Spring, 1959), 43-74.

[15] Rogers, Andrei. "A Regression Analysis of Inter-regional Migration in California." Review of Economics and Statistics, 49 (May, 1967), 262-267.
[16] Sjaastad, Larry A. "The Costs and Returns of Human Migration." Journal of Political Economy, 70 (October, 1962), 80-93. [17] Stouffer, Samuel A. "Intervening Opportunities: A Theory Relating Mobility and Distance." American Sociological Review, 5 (December, 1940), 845-867.

[18] . "Intervening Opportunities and Competing Migrants," Journal of Regional Science, 2 (April, 1960), 1-26.

[19] U.S. Bureau of the Census. Census of Population: 1970. State Economic Areas, Final Report PC(2)-10B, Washington, D.C., U.S. Government Printing Office, 1972.

[20] U.S. Bureau of the Census. Census of Population: 1970. Subject Reports, Migration Between State Economic Areas, Final Report PC(2)-2E. Washington, D.C., U.S. Government Printing Office, 1972.

[21] U.S. Bureau of the Census. U.S. Census of Population: 1960. Selected Area Reports. State Economic Areas. Final Report PC(3)1A. U.S. Government Printing Office, Washington, D.C. 1963.

[22] U.S. Bureau of the Census. U.S. Census of Population: 1960. Subject Reports. Mobility for States and State Economic Areas. Final Report PC(2)-2B. U.S. Government Printing Office, Washington, D.C., 1963.

[23] Wadcki, Walter J. "Alternative Opportunities and Interstate Migration: Some Additional Results." Review of Economics and Statistics, 56 (May, 1974), 254-257.

[24] _. "A Note on Opportunity Costs and Migration Analysis." The Annuals of Regional Science, 8 (February, 1974), 109117. 